\title{
Engineering geology of cross-Himalayan railway alignment and its preliminary design
}

\author{
Zhen-ming Shi', *Megh Raj Dhital ${ }^{2}$, Yuan-yuan Zhou'1, Wei-ran Liu' ${ }^{1}$, Qing-zhao Zhang1, and Dan-xuan Xue ${ }^{1}$ \\ ${ }^{1}$ Department of Geotechnical Engineering, Tongji University, Shanghai, China \\ ${ }^{2}$ Department of Geology, Tri-Chandra Multiple Campus, Tribhuvan University, Ghantaghar, Kathmandu, Nepal \\ *Corresponding author: mrdhital@gmail.com
}

\begin{abstract}
The Belt-and-Road initiative foresees the construction of transportation routes across continents. One of such railway routes is planned from Tibet (China) through the Himalayan Range to Nepal and India, and envisaged to be one of the most important economic corridors. Based on the field investigation, this paper analyses the engineering geological conditions along the proposed route and proposes a preliminary design of the alignment. The alignment starts from Dingri (Tingri) via Jilong from Tibet and ends in Kathmandu, with a total length of $357 \mathrm{~km}$. Based on the geological and geomorphic characteristics, the alignment can be divided into five zones: the mid mountain and wide valley, mid mountain and narrow valley, alluvial fans, tunnel crossing, and, respectively. The railway alignment encounters glaciers, snow and rock avalanches, collapses, landslides, outburst floods and debris flows. There are also many faults, folds and other geological structures together with steep and extensive slopes and long tunnels with a high overburden
\end{abstract}

Keywords: Cross-Himalayan railway alignment, engineering geological conditions, alignment design, Engineering measures

Paper Received: 15 Dec 2017

Paper Accepted: 29 May 2018

\section{INTRODUCTION}

The main goal of Belt-and-Road initiative is to achieve the construction and connectivity of infrastructures, such as transportation, energy pipelines and ports, to improve the degree of global trade and facilitate investment.

South Asia is one of the key areas for Belt-and-Road initiative. In recent years, India is China's largest trading partner in South Asia, whereas Nepal is located between China and India. The large-scale economic exchanges between the two countries are limited due to the gigantic natural barrier of the Himalaya.

About $90 \%$ of the goods between China and India are transported by sea. Although shipping has a strong transport capacity and low costs, but the transport time is longer and is vulnerable to typhoons and other extreme weather conditions. Compared to the cross-Himalayan railway transport, the existing marine transportation system unnecessarily increases the transit time and cost.

As a landlocked country, Nepal's special geographical location and terrain have led to traffic inconveniences. At present, the freight between China and Nepal is mainly completed through the China-Nepal roads (Fig. 1). Some parts of the road are in bad conditions and vulnerable to landslides, debris flows and other geological disasters in the rainy season which result in frequent blockages and accidents. In addition, the road capacity is close to saturation. Hence China, Nepal and India are in urgent need of a railway alignment across the Himalaya to change the status of traffic inconvenience (Gu et al., 2014).
The Himalaya is the world's youngest, largest and active continental orogenic belt formed by the collision of Indian and Eurasian plates. The geological conditions in this area are complex (Gansser, 1964; Yin, 2001; Deng, 2014; Dhital, 2015), and geological disasters occur frequently (Goel et al., 1995). On the other hand, the infrastructure of the surrounding areas is lagging behind, which makes it very difficult for the construction of the cross-Himalayan railway. Therefore, based on the field investigation, this paper analyzes the engineering geological conditions of the alignment, proposes a preliminary design and provides some recommendations and suggestions for the construction of the cross-Himalayan railway.

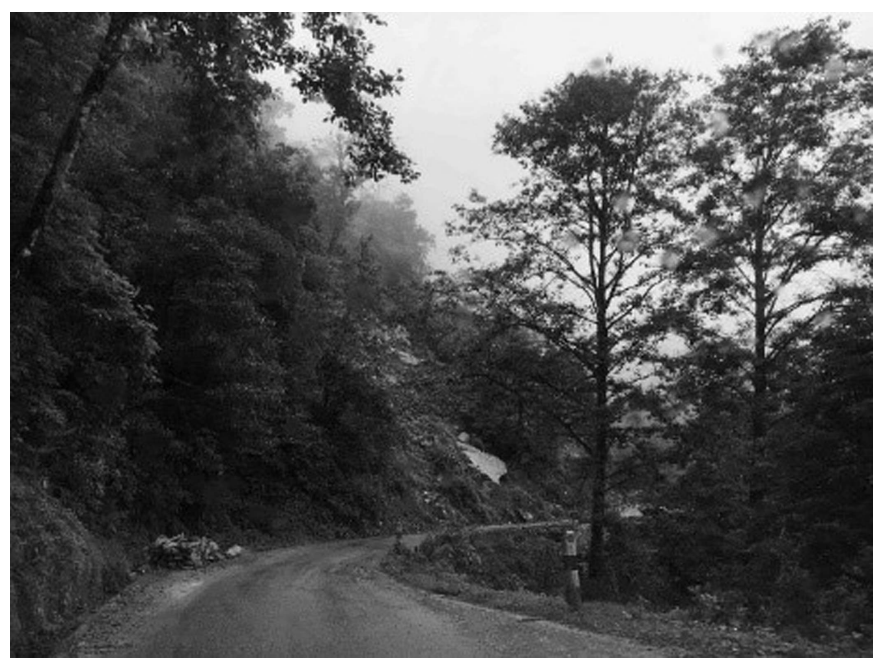

Fig. 1: The status of China-Nepal highway 


\section{ALIGNMENT DESIGN PRINCIPLES}

Based on the standard design principles as well as the experience of Qinghai-Tibet railway and the Lhasa-Xigaze railway, the following technical standards and alignment selection criteria are recommended.

1) The number of main track: single track

2) Targeted speed: $80 \mathrm{~km} / \mathrm{h}$ for the frozen earth; 120 $\mathrm{km} / \mathrm{h}$ for the non-frozen earth

3) The minimum curve radius: $300 \mathrm{~m}$

4) Limiting gradient: $15 \%$; afterburning gradient: $30 \%$

5) Traction mode: electric traction

6) Block mode: semi-automatic relay block

In the vicinity of Gyironggou, the valley is narrow and the slope gradient is extremely high. The straight alignment from the Gyirong County to Kathmandu is close to $130 \mathrm{~km}$, where the elevation drop is about $2800 \mathrm{~m}$. Because of the east-west trending faults at Gyironggou, it is not suitable for the east-west trending alignment to reduce its grade. Based on the above two factors, it is recommended that electric power traction should be applied. Here, the limiting gradient should be $15 \%$, and the afterburning gradient should be $30 \%$. At the same time, the alignment crosses the Himalayan range, and there are inevitably large lengths of tunnels. If an internal combustion engine is used, tunnel ventilation is required, which limits the length of the tunnel. Hence electric traction should be used.

The main portion of the alignment should be close to the existing road (such as the National Highway No. 318 and County Road No. 214), since it can facilitate the entry and transfer of equipment and personnel. The railway also needs to be close to the town (such as Dingri and the Gyirong county) to facilitate the constructors' livelihood. The selection of tunnel portals and bridge sites should also consider the convenience of construction and the appropriate working surface. The route can be used as far as possible through the main cities in the area to achieve maximum economic benefits.

\section{General trend of alignment}

The railway alignment from the Dingri County to Kathmandu was selected according to the above principles of alignment selection, and the general route is as follows: It starts from the Dingri (Tingri) county, runs along the National Highway No. 318 to Xiamude, and then along the County Road No. 214 to the south bank of Pektsoo, and after crossing the Mara Mountains reaches the Gyirong county, and then goes via Gyironggou across the Himalaya, through the China-Nepal border town of Gyirong into Nepal, and finally reaches the capital Kathmandu (Fig. 2). The total length of alignment is $357 \mathrm{~km}$. Taking into account the differences in geological and

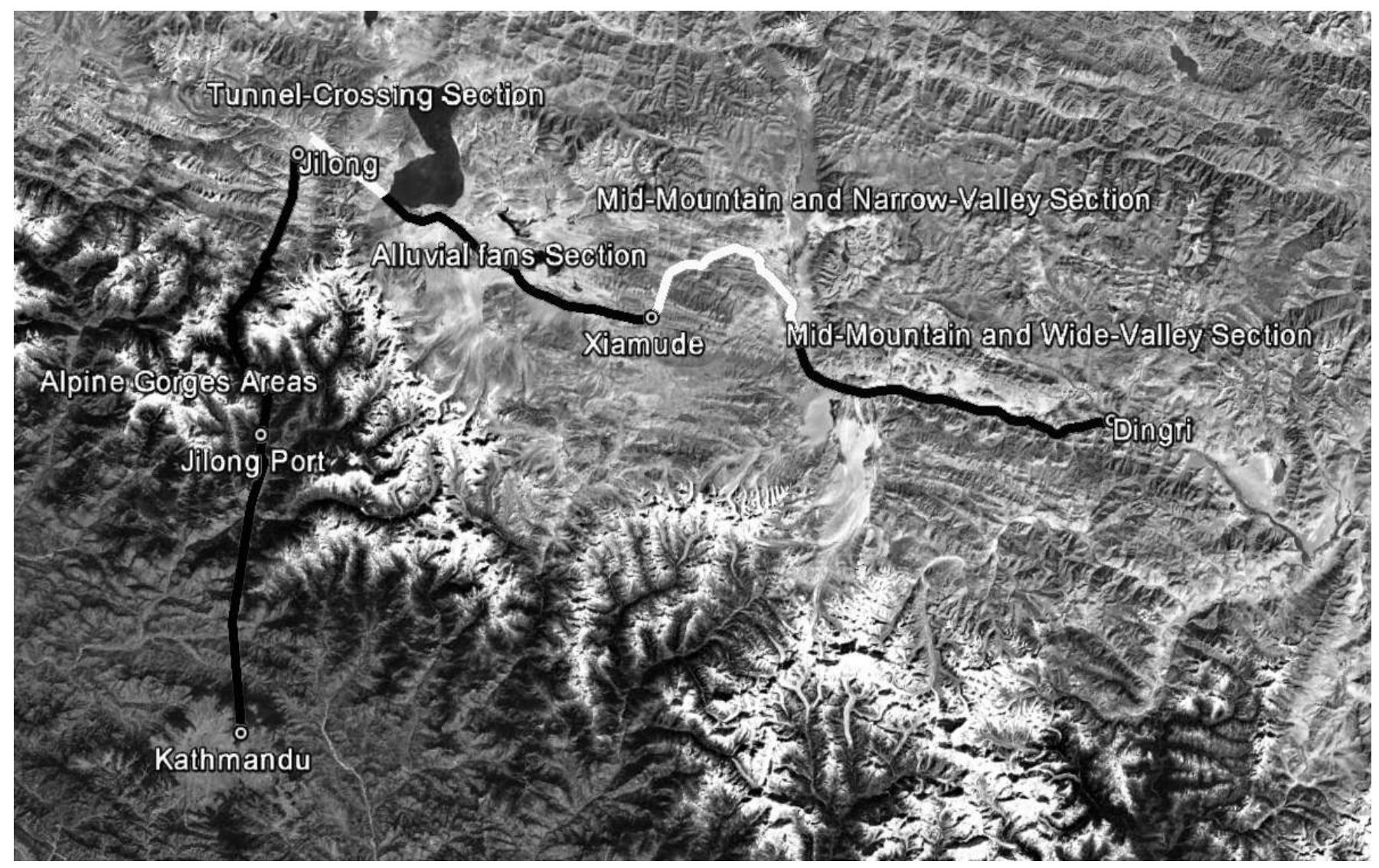

Fig. 2: Overall route and section partition 


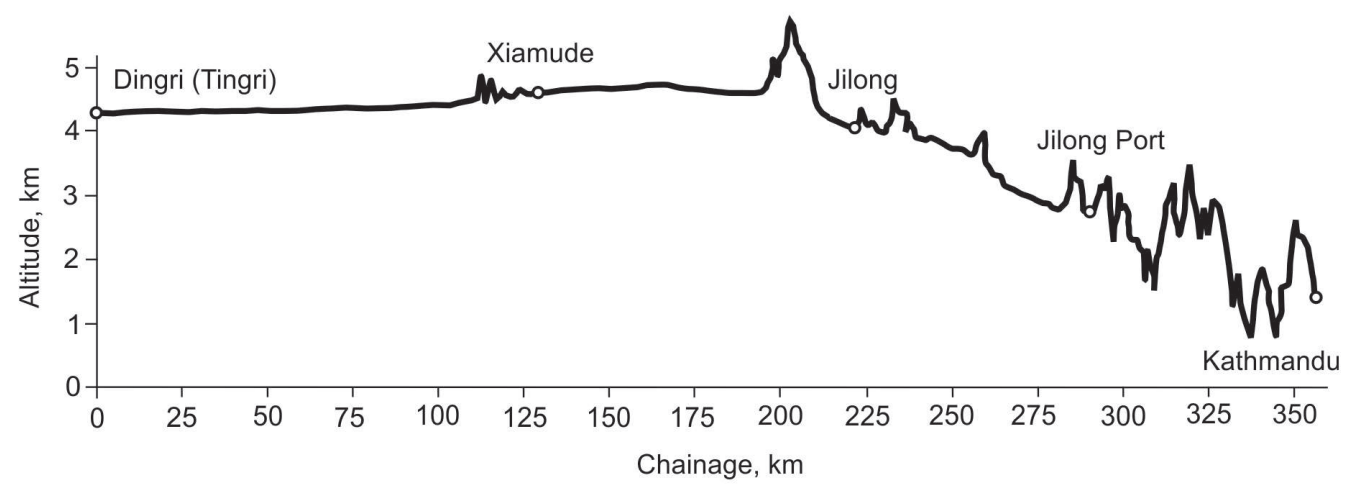

Fig. 3: Overall alignment and elevation variation

geomorphic units, the alignment can be divided into the following five zones: 1) mid mountain and wide valley, 2) mid mountain and narrow valley, 3) alluvial and diluvial fans, 4) tunnel crossing, and 5) alpine gorge. The overall route and section partitions are shown in Fig. 2 and the elevation of the overall alignment is shown in Fig. 3.

\section{ENGINEERING GEOLOGICAL CONDITIONS AND CONTROL MEASURES}

A summary of engineering geological conditions and proposed control measures are based on preliminary field study and the investigation of satellite images. The main characteristics of the five sections are as following.

\section{Mid mountain and wide valley section}

The mid mountain and wide valley section encompasses the stretch between Dingri and the Gucuo village (AK0 to AK98), with the total length of $98 \mathrm{~km}$, accounting for $27.45 \%$ of the total length of the alignment. This section goes through both banks of the Pum Qu River, nearly along the National Highway No. 318. The alignment varies in altitude from 4264 to $4401 \mathrm{~m}$ and steadily ascends along the valley with minor undulations. The valley is mostly between 2 and $6 \mathrm{~km}$ wide. There is an alluvial fan with a width of about $11.5 \mathrm{~km}$ near the Ganga village (Fig. 4). In this stretch, it is necessary to strengthen the subgrade, make good drainage and protect slopes from river scouring. Medium and small bridges will be required to cross the middle section of the alignment which is prone to river erosion. There are debris flows in some areas of this section, which need to be further investigated for their propagation and runout distances. Their influence on the railway alignment should be investigated in detail, so as to choose the appropriate control and mitigation measures. For medium and small debris flows, single-span bridges can be used to cross the runout area of debris flow, but the terrain conditions and longitudinal slope need to be considered. When the valley is wide and the debris flow channel is far away from the river, the route can be set in the outer margin of the diluvial (talus) fan, setting up diversion dikes, and crossing the distal part of the fan by a bridge. If the debris flow is large and the diluvial fan has extended up to the river, it could be difficult to regulate it, and it is recommended to divert the alignment via the other bank of the river or to construct a tunnel according to the prevailing geological conditions.

\section{Mid mountain and narrow valley section}

The mid mountains and narrow valley section is the area from the Gucuo village to Xiamude town (AK98-AK128), with a total length of $30 \mathrm{~km}$, accounting for $8.40 \%$ of the total length of the alignment. This section is also located on both banks of the Pum Qu River, close to the National Highway No. 318. The altitude of the alignment varies between 4400 and $4592 \mathrm{~m}$, which has minor oscillations and continues climbing on the valley floor (Fig. 5). The width of the valley is mostly between 0.5 and $1.0 \mathrm{~km}$. The alignment cannot be placed in the narrow part of the valley and needs to be traversed by tunnels. The development and influence of debris flows in some areas of this section should be investigated in detail.

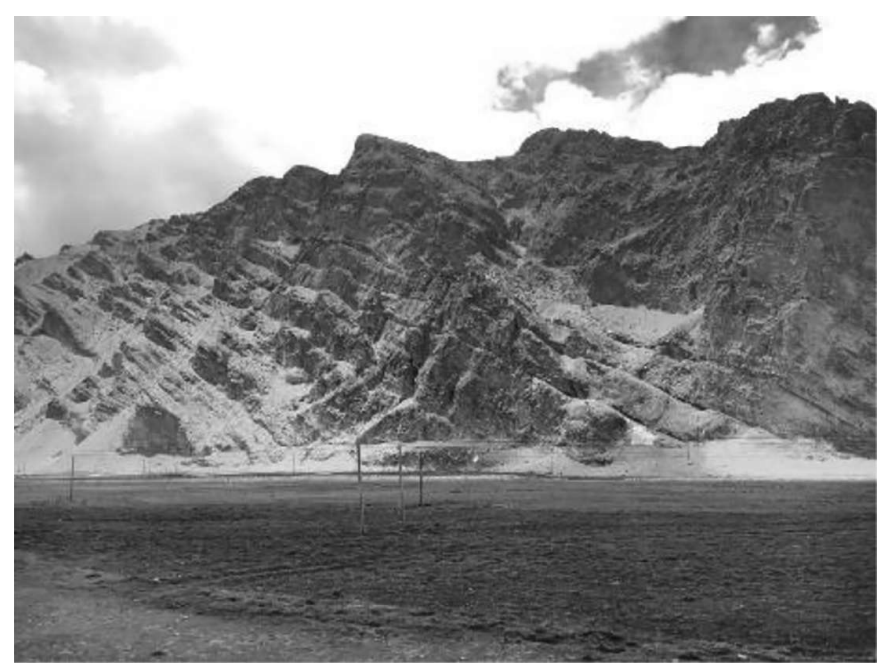

Fig. 4: The topography of mid-mountains and wide-valley section 


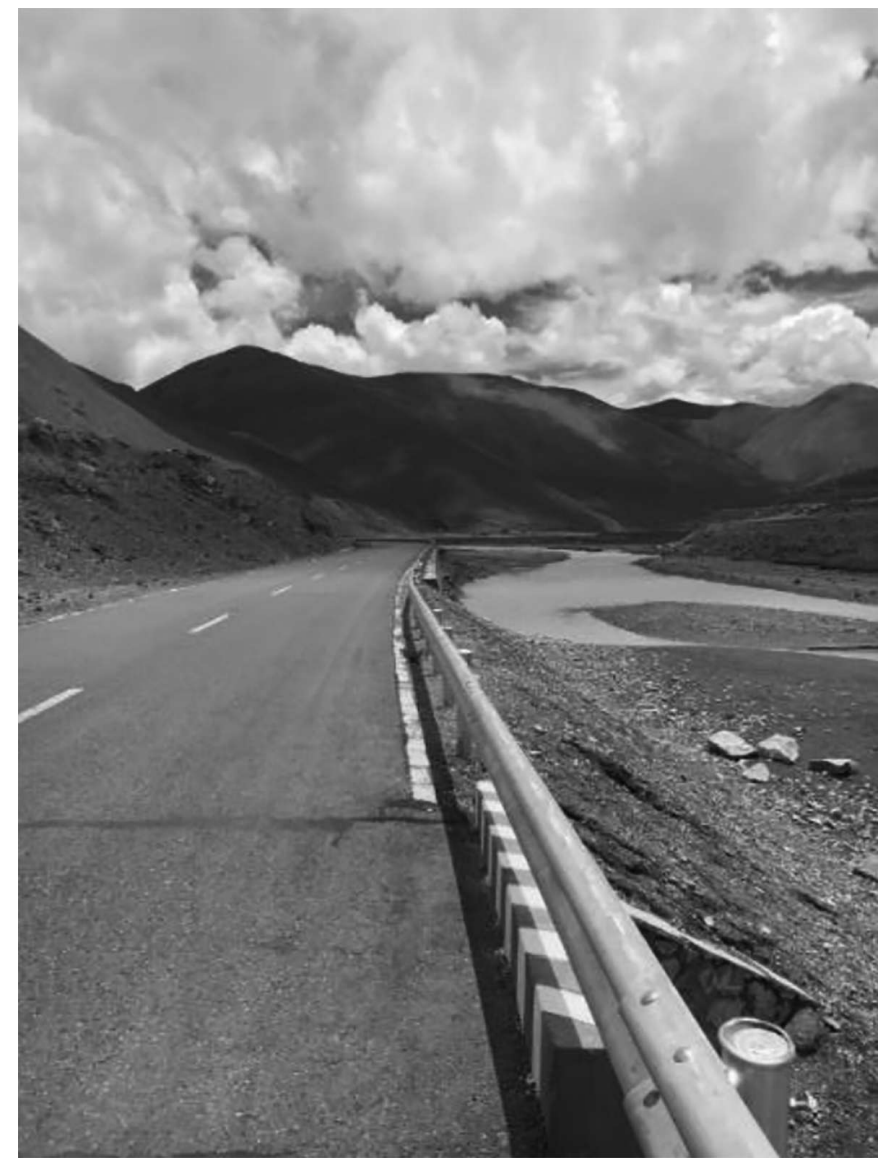

Fig. 5: The topography of mid mountain and narrow valley section

\section{Alluvial and diluvial fan section}

The section of Xiamude to Pektsoo (AK128-AK194) is a large range of alluvial and diluvial fans, which is $66 \mathrm{~km}$ long, runs along the County Road No. 214, and accounts for $18.49 \%$ of the total length of the alignment. The south side of this section is the Himalaya, and the north side is lakes Langqiangcuo and Pektsoo, which were formed by the meltwater from Mount Shisha Pangma (Fig. 6). The altitude of the alignment ranges between $4594 \mathrm{~m}$ and $4735 \mathrm{~m}$. The section is essentially flat and wide, with a high ground in the middle and lower elevations on both sides. It is also necessary to strengthen the subgrade, make good drainage and carry out slope protection measures to prevent the riverside from scouring. Medium and small bridges would be necessary to cross the middle section, which is frequently washed away by the river.

\section{Tunnel crossing section}

The section of Pektsoo to Gyirong (AK194-AK215) is broken by the Kuntang Lahm Mountains. This section is $21 \mathrm{~km}$ long, accounting for $5.88 \%$ of the total length of the alignment. The main topography is shown in Fig. 7 and the altitudinal change is shown in Fig. 8. Here, it is necessary to build a long tunnel to pass through this section. The tunnel is about $19.0 \mathrm{~km}$

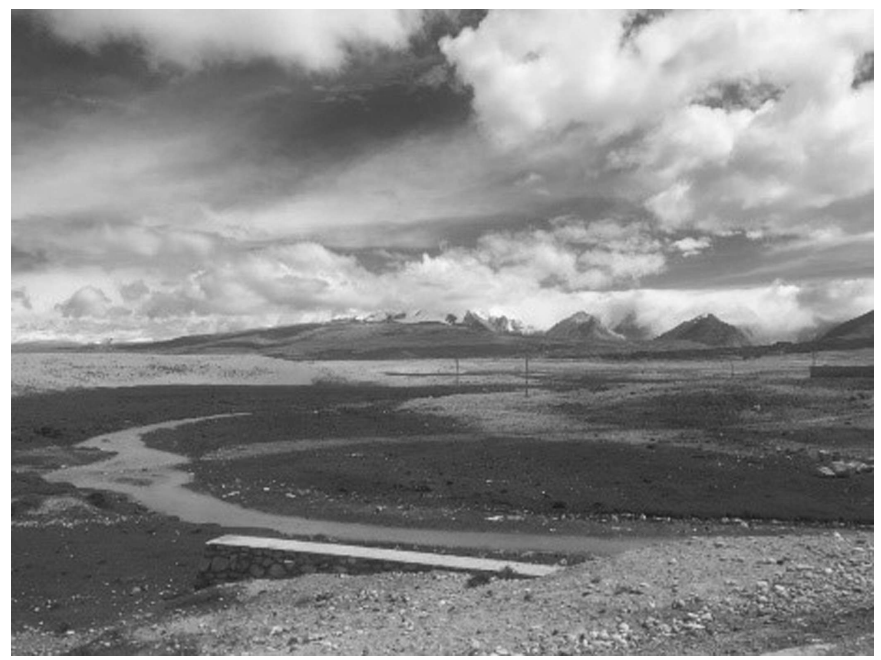

Fig. 6: The topography of alluvial and diluvial fan section

long which is the second longest tunnel in this alignment. The surface projection of the alignment in the section is between $4160 \mathrm{~m}$ and $5718 \mathrm{~m}$, and the tunnel elevation is between 4608 $\mathrm{m}$ and $4178 \mathrm{~m}$, with unilateral decline. The maximum tunnel depth is $1290 \mathrm{~m}$, and the tunnel surrounding rock is mainly composed of medium hard grey micrite and sandstone. The intersection angle between tunnel axis and fold axis is about $30^{\circ}$. According to the strata character, the direction and depth of the tunnel should be properly adjusted to make it pass through the two wings of the fold. Several east-west trending faults outcrop to the surface on Mala Mountain, the extended length of which is about $15 \mathrm{~km}$. They are exposed to the trend of northsouth fault which exposed length is about $20 \mathrm{~km}$. The tunnel is inevitably required to cross the fault fracture zone, and the two groups of faults are almost orthogonal, so oblique crossing is adopted.

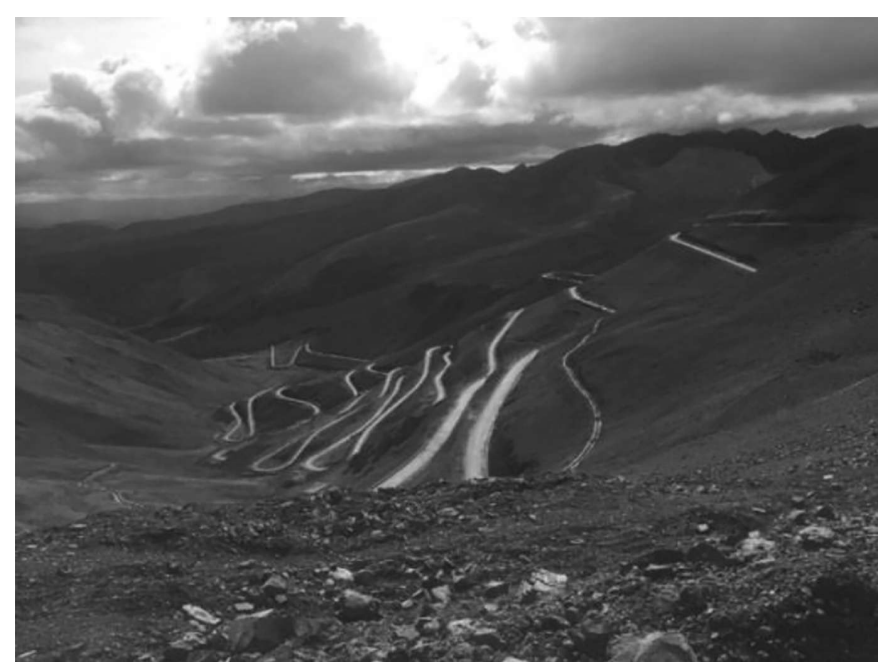

Fig. 7: The topography of tunnel crossing section 


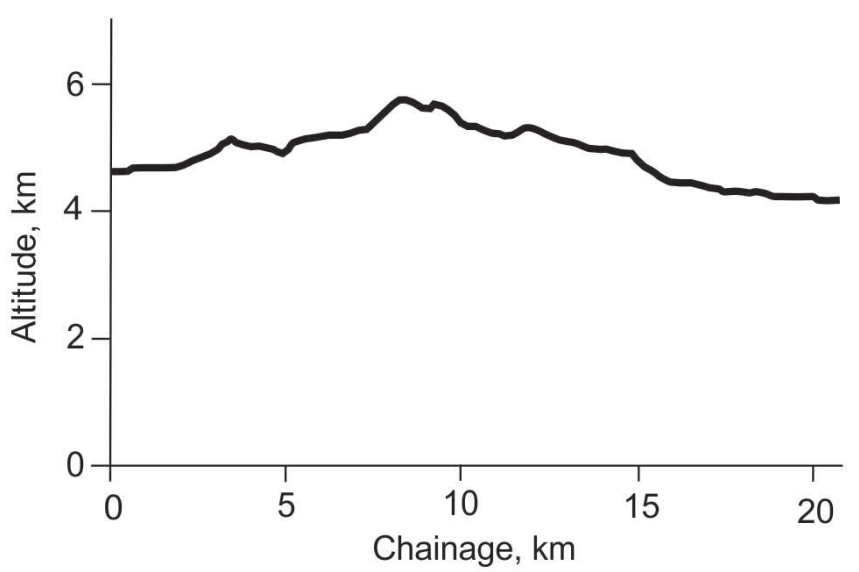

Fig. 8: Elevation variation of tunnel crossing section

\section{Alpine gorge section}

The alignment in this section (AK215-AK357) is along the Gyirong valley from the Gyirong county to the village of Old Shaybru Besi where the alignment moves away from the valley to Kathmandu. The length is $142 \mathrm{~km}$, accounting for $39.78 \%$ of the total alignment length. Most of this section is the Alpine gorge area, located on the banks of the Jilongzangbu, with high mountains and deep gorges. The distance from Gyirong to Kathmandu is close to $130 \mathrm{~km}$, and the elevation drop is about $2800 \mathrm{~m}$, with a great longitudinal gradient. The main topography is shown in Fig. 9 and the elevation change is shown in Fig. 10. The width of gorge is mostly less than $100 \mathrm{~m}$, and a tunnel is proposed in a narrow or a bend frequently encountered in the gorge. The altitude of the alignment is between $4178 \mathrm{~m}$ and $1074 \mathrm{~m}$, steadily descending to the low-lying area (AK336) first and then moving up to Kathmandu. Therefore, an afterburning gradient of $30 \%$ in opposite direction can be adopted respectively at the steepest slope in the two sections of AK260-AK336 and AK345-AK357. Between AK241 and AK285, there are more than eight east-west trending faults crossing the gorge, which are distributed with over $6000 \mathrm{~m}$ snowy mountains at the same time. Thus, it is difficult to avoid the problems, such as the alignment parallel to the faults and tunnel depth too deep. So the best choice is that down along the gorge, vertical crossing the fault, use tunnel to pass through the narrow bend and afterburning slope to overcome high gradients. Because the alignment is short from the river bank and span Jilongzangbu many times, it is recommended to replace railway by bridge in this section. The height of deck should be 0.5-1.0 m higher than the highest flood level. Between AK299 and AK336, there is a tunnel with a length of $27 \mathrm{~km}$, a maximum burial depth of $2000 \mathrm{~m}$, which is the biggest difficulty in this alignment. The surrounding rock of tunnel is mainly composed of hard quartzite, gneiss and marble, which is prone to rock burst.

With the faults development, rock avalanches, rock falls, landslides and debris flows are frequent in the Gyirong valley. This section has the most complex geological conditions and difficulties in construction.

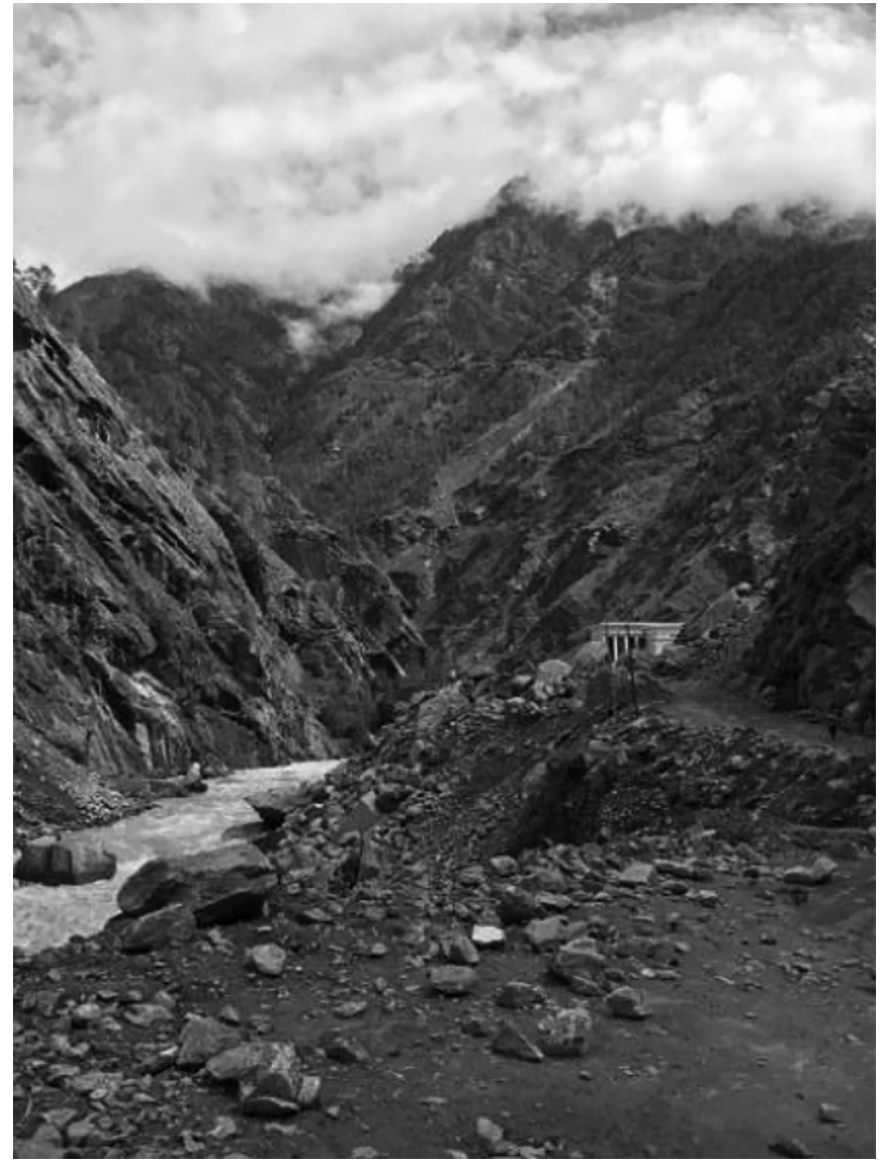

Fig. 9: The topography of Alpine gorge section

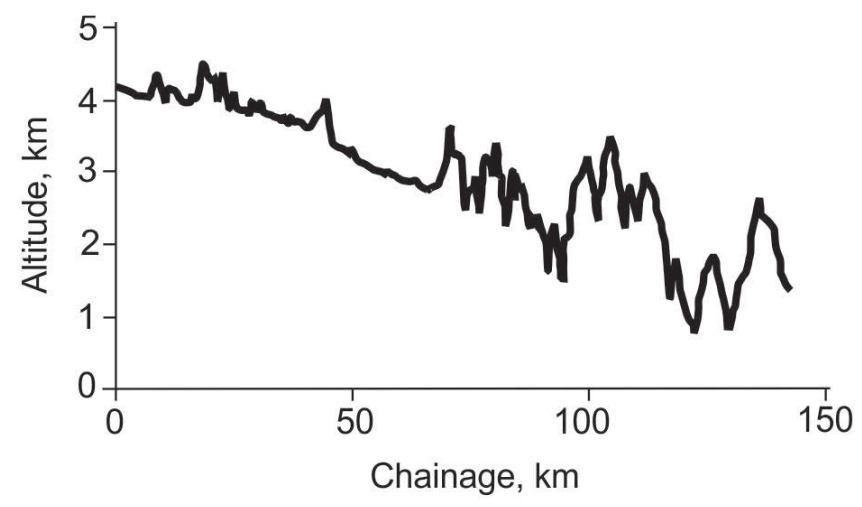

Fig. 10: Elevation variation of Alpine gorge section

\section{DISCUSSIONS AND CONCLUSIONS}

This paper reveals that the total length of tunnels and bridges is $173.3 \mathrm{~km}$, accounting for $48.54 \%$ of the total alignment length. There are 17 tunnels, the maximum length of which is $25 \mathrm{~km}$ and the maximum overburden is $2000 \mathrm{~m}$ (Table 1). There are nine bridges, with the maximum length of $3.2 \mathrm{~km}$ and the maximum height of $320 \mathrm{~m}$ (Table 2). 
Table 1: Data of main tunnels

\begin{tabular}{cccc}
\hline Start point & End point & $\begin{array}{c}\text { Length } \\
(\mathbf{k m})\end{array}$ & $\begin{array}{c}\text { Overburden } \\
(\mathbf{m})\end{array}$ \\
\hline AK111+100 & AK113+500 & 2.4 & 360 \\
AK114+300 & AK116+500 & 2.2 & 240 \\
AK122+600 & AK125+100 & 2.5 & 80 \\
AK194+000 & AK213+600 & 19.6 & 1290 \\
AK223+000 & AK224+900 & 2.9 & 240 \\
AK225+200 & AK226+600 & 1.4 & 130 \\
AK226+700 & AK228+100 & 1.4 & 160 \\
AK230+500 & AK238+700 & 8.2 & 620 \\
AK238+900 & AK240+000 & 1.1 & 160 \\
AK255+700 & AK260+600 & 4.9 & 570 \\
AK281+200 & AK288+200 & 7.0 & 910 \\
AK289+400 & AK291+100 & 1.7 & 400 \\
AK292+100 & AK296+600 & 4.5 & 810 \\
AK296+600 & AK301+100 & 4.5 & 700 \\
AK308+900 & AK334+500 & 25.6 & 2000 \\
AK337+700 & AK342+200 & 4.5 & 580 \\
AK344+900 & AK355+100 & 10.2 & 1250 \\
\hline & & &
\end{tabular}

Geological disasters, such as rock falls, landslide, debris flows, snow and rock avalanches and permafrost are widely distributed in the whole alignment, and appropriate control measures should be taken according to the requirements.

Folds and faults are mainly developed in the tunnelcrossing section and Alpine gorge section, especially the longitudinal faults crop out in the Mala Mountains and the more than eight east-west faults across the gorge in AK241-AK285. It is inevitable that the tunnel needs to pass through the fault or fracture zone.

There are large longitudinal slopes of the alignment, and the altitude is drastically changed in the Alpine gorge section. The railway track reaches the limiting gradient of $30 \%$ in the two sections of AK260-AK336 and AK345-AK357.

The tunnels are long and have a large overburden. The largest tunnel is $25.6 \mathrm{~km}$ long and the maximum overburden is $2000 \mathrm{~m}$ and the deep tunnels are prone to rock burst. All these seriously challenge the construction of Cross-Himalayan railway alignment.
Table 2: Data of main bridges

\begin{tabular}{llcc}
\hline \multicolumn{1}{c}{ Start point } & End point & $\begin{array}{c}\text { Length } \\
(\mathbf{k m})\end{array}$ & $\begin{array}{c}\text { Height } \\
(\mathbf{m})\end{array}$ \\
\hline $\mathrm{AK} 1+300$ & $\mathrm{AK} 4+100$ & 2.8 & 15 \\
$\mathrm{AK} 113+500$ & $\mathrm{AK} 114+300$ & 0.8 & 10 \\
$\mathrm{AK} 125+100$ & $\mathrm{AK} 125+700$ & 0.6 & 15 \\
$\mathrm{AK} 288+200$ & $\mathrm{AK} 289+400$ & 1.2 & 230 \\
$\mathrm{AK} 290+900$ & $\mathrm{AK} 291+900$ & 1.0 & 300 \\
$\mathrm{AK} 304+900$ & $\mathrm{AK} 305+800$ & 0.9 & 300 \\
$\mathrm{AK} 307+200$ & $\mathrm{AK} 308+900$ & 1.7 & 290 \\
$\mathrm{AK} 334+500$ & $\mathrm{AK} 337+700$ & 3.2 & 320 \\
$\mathrm{AK} 342+200$ & $\mathrm{AK} 344+900$ & 2.7 & 310 \\
\hline
\end{tabular}

\section{ACKNOWLEDGEMENTS}

We are grateful to Tongji University, Shanghai, China, and to Tri-Chandra Multiple Campus of Tribhuvan University, Ghantaghar, Kathmandu, Nepal, for research facilities. We sincerely acknowledge the support of Prof. Dr. S. M. Rai and constructive suggestions from Mr. Uttam Bol Shrestha and an anonymous reviewer who greatly helped to improve this paper.

\section{REFERENCES}

Deng, O, Cheng, S., and Ma, J., 2014, Seismic activities and earthquake potential in the Tibetan plateau. Chinese Journal of Geophysics, 2014, v. 57(7), pp. 2025-2042 (in Chinese).

Dhital, M. R., 2015, Geology of the Nepal Himalaya. Regional Perspective of the Classic Colliede Orogen. Springer, Switzerland, $498 \mathrm{p}$.

Gansser, A., 1964, Geology of the Himalayas. Interscience, New York, 289 p.

Goel, R. K., Jethwa, J. L., and Paithankar, A. G., 1995, Tunnelling through the young Himalayas - A case history of the Maneri-Uttarkashi power tunnel. Engineering Geology, v. 39(1-2), pp. 31-44.

Gu, F., Shi, Z., Zhang, Y., and Bai, Y., 2014, Study on feasibility of China-Nepal-India railway crossing Himalayas. Journal of Tunnel Construction, v. 77, pp. 653-660 (in Chinese).

Yin, A., 2006, Cenozoic tectonic evolution of the Himalayan orogen as constrained by along-strike variation of structural geometry, exhumation history, and foreland sedimentation. Earth-Science Reviews, v. 76, pp. 1-131. 